Research Article

\title{
An Innovative Methodological Approach for Monitoring and Chemical Characterization of Odors around Industrial Sites
}

\author{
A. Di Gilio (D, J. Palmisani, and G. de Gennaro \\ Department of Biology, University of Bari Aldo, Moro, Via Orabona 4, 70126 Bari, Italy \\ Correspondence should be addressed to G. de Gennaro; gianluigi.degennaro@uniba.it
}

Received 31 July 2018; Revised 18 September 2018; Accepted 30 September 2018; Published 21 October 2018

Academic Editor: Helena A. Flocas

Copyright (c) 2018 A. Di Gilio et al. This is an open access article distributed under the Creative Commons Attribution License, which permits unrestricted use, distribution, and reproduction in any medium, provided the original work is properly cited.

\begin{abstract}
This study aims to highlight the potentialities of an innovative methodological approach for monitoring and chemical characterization of odors, especially in high concern and complex industrial areas. The proposed approach was developed in order to monitor and identify odor-active compounds responsible for odor annoyance coming from different industrial activities such as landfills, wastewater treatment plants, and petroleum plants. The methodology's strengths are as follows: (1) the tailored approach for each typology of industrial areas/sites; (2) integration of technologies able to provide real-time information about the emissive sources; (3) mapping of air pollutants on the territory aimed to identify and discriminate among different fugitive emissions responsible for odor annoyance; (4) collection of more representative air samples only during the nuisance events, thanks to the implementation of innovative sampling systems and citizens' involvement; and (5) increased analytical sensitivity in odor-active VOCs detection. This methodology reveals to be a useful tool to collect real-time information about the emission sources and their impacts on the surrounding area giving credit to citizens' complaints. Moreover, it allows to overcome the limitations of the conventional approaches related to the lack of instrumental sensitivity and to identify the chemical compounds contributing to the odor annoyance.
\end{abstract}

\section{Introduction}

Nowadays, odor emissions and their monitoring and control are an issue of concern for scientific community and stakeholders. In fact, during the last decades, the number of published scientific studies focused on the identification of the odor-active compounds emitted by different sources and on their correlation with the human perception is considerably increased [1-3]. More specifically, the interest about odor emissions stems from the growing public reactions and complaints of the citizens living near complex industrial areas and perceiving the odors as a serious threat to their health [4-9]. Environmental malodor in fact could impose physical, psychological, social, and behavioral stress to humans. As a consequence, respiratory symptoms and health impairment could be verified even at odorant exposures below irritation thresholds. Moreover, during the last 50 years, the intensification of industrial plants such as landfills, composting plants, wastewater treatment plants, petroleum refineries, and livestocks in addition to population growth and residential development at the peripheral and rural areas have increased the number of residents exposed to odors [10-13]. This issue is also exacerbated by the difficulty in assessing and regulating odor emissions because odor perception is subjective and the result of the complex interaction of odorant gases in a mixture, which depends on the concentration of individual odorants, on interaction effects, and on individual-specific factors of the exposed subject $[14,15]$. Moreover, the assessment of odor represents an environmental issue of great complexity because of the causal relationship between odor events (often characterized by a brief duration) and odor sources. Therefore, in order to obtain an exhaustive comprehension of the odor emission phenomena, high time resolution, accurate, reliable, and reproducible experimental data are needed [16]. Nowadays, the most used methodology for odor emission assessment is dynamic olfactometry. This technique allows to obtain measurements of odor concentrations but is not addressed to discriminate each odoractive compound and the relative contribution to the overall 
odor concentration. Moreover, due to high temporal variability of odor emissions, the air samples collected for olfactometric analysis could not be representative of real annoyance perceived by citizens because they are often collected only after citizen alerts and complaints. Dynamic olfactometry is also a time-consuming and quite expensive technique, so it cannot provide high temporal and spatial resolution measurements and accurately identify and localize emission sources especially in complex industrial areas consisting of several fugitive emission sources $[17,18]$. For this reason, in order to overcome this lack, over the last decades, electronic noses have been developed and are nowadays recognized as a good option when high temporal resolution monitoring of odorous events is needed to identify short-term events or occasional odor emissions $[16,19]$. Anyway, it is important to underline that both dynamic olfactometry and electronic noses do not allow the qualitative and quantitative chemical characterization of volatile odor-active compounds, not providing useful information about emission sources and their recognition. Therefore, for the specific purposes of environmental odor emissions monitoring, a synergistic approach integrating different analytical methodologies and technologies is the best way to identify odor sources, to elucidate the mechanism of formation and abatement strategies, and to manage odor annoyance deriving from industrial activities $[16,18,20]$.

The objective of this study is to highlight the strengths of innovative and integrated methodological approaches developed ad hoc to face specific issues related to odor emissions. In order to show potentialities and strengths, preliminary results coming from two applications in the field of new technology-based devices and methodological approaches are thus reported in the paper. Two monitoring campaigns were carried out, each one in a specific and complex industrial site. The first monitoring campaign was carried out near a solid urban waste plant. The application of the methodological approach in this first study case was mainly addressed to the identification of the odor-active compounds responsible for odor annoyance. The second monitoring campaign was carried out in the industrial area of Viggiano, a small village in the south of Italy, where the largest Italian gas and oil pretreatment plant is placed. The aim of this second study case was the source identification and localization in order to accreditate the citizen complaints related to odor annoyance.

\section{Results and Discussion}

2.1. Methodological Approach and Experimental Design. In this study, innovative methodological approaches able to both identify odor source emissions and characterize odoractive compounds responsible for odor annoyance coming from two different industrial activities (an urban solid waste plant and a gas/oil pretreatment plant) are developed. More specifically, in order to address specific issues, the experimental design was developed ad hoc taking into account both the typology of the industrial activity and the proximity to the surrounding populated settlements. Near landfills or wastewater treatment plants, where no different emission sources coexist, a tailored and integrated system consisting of (a) a sensor for volatile organic compounds (VOCs) and/or odor-active compounds monitoring, (b) a system for meteorological parameters monitoring, and (c) a remotely controlled automatic air sampling device was developed in order to characterize odor emission sources. On the contrary, when the site under investigation is a complex industrial area characterized by several fugitive emission sources, a high temporal and spatial integrated approach was developed and tested on field in order to map the territory and to identify both long- and short-term pollution events. The strength of both proposed approaches consisted in citizen involvement. In fact, the monitoring systems were integrated with a telephonic system that systematized the population complaints. Each citizen (called the receptor) was georeferenced on the map and using a telephone switchboard, communicated the odor perception and also its intensity choosing among three levels of intensity. The phone call was recorded and displayed on the map in real time on a website. The setting of specific routine, based on the number of calls for the index of intensity in a specific period of time and on threshold values of VOCs and/or odor concentration, allowed to remotely activate the sampling systems located in the area interested by odor annoyance. The sampling devices promptly collected air samples inside Nalophan bags, and the information about the sampling activation was immediately sent by text messages to the technical operators that can pick up the sample and prepare the olfactometric measurement according to the technical law EN 13725/2003 [21]. The air sampling only during significant events of odor annoyance allowed to collect samples that were more representative of real human perception and to overcome the limitation due to the analytical performances. In order to highlight the potentiality of these methodological and integrated approaches for odor monitoring and characterization, the preliminary results of two monitoring campaigns are reported in this study.

\subsection{Case Study 1: Chemical Characterization of Odors in an} Urban Solid Waste Plant. Air samples near an urban solid waste plant, in correspondence with critical odor events pointed out by citizen calls, were collected inside Nalophan bags and analyzed using a thermal desorber UNITY $2^{\mathrm{TM}}$ (Markes International Ltd.) connected to a gas chromatograph (GC Agilent 7890) equipped with an olfactometric port (ODP 3 Gerstel) and connected to a mass spectrometer (MS Agilent 5975). After the GC separation, the column flow was splitted with the ratio $1: 1$, one part was led to the MS system and the other one to ODP. The effluent from the capillary column reached the olfactometric port through an uncoated transfer line (e.g., deactivated silica capillary) and was sniffed by the assessors in a PTFE conical port, fitted to the shape of a nose. The transfer line was heated to prevent the condensation of compounds on the walls of the capillary. Auxiliary gas (make-up gas) was added to the GC effluent to prevent the drying of the assessors' nose mucous membranes, which could cause discomfort especially in longer 
analyses. Two trained panelists were asked to indicate when odor was perceived and the duration of the odor activity and to describe with clear words the quality and the intensity of the perceived odor. The identification of odor-active VOCs was performed by comparing the mass spectra of the unknown compounds with those listed in the NIST library (Agilent Technologies). The identification was considered valid only if the confidence rating of mass spectra comparison was superior or equal to $95 \%$. The attribution was further confirmed using the retention times of authentic compounds, when applicable. Experimental data allowed both to obtain a complete qualitative screening and to identify odor-active VOCs. For example, the analysis of one sample collected downwind at the urban solid waste in correspondence with 5 calls characterized by high intensity and derived from citizens living in the near urban area is reported in Figure 1. The overlapping of GC/MS chromatogram (TIC) with aromagram (green) is shown. VOCs detected, retention time (expressed in min), odor description, and intensity are listed in Table 1 . The intensity of odor-active VOCs detected by the assessors sniffing at the ODP was described on the basis of an odor intensity scale, ranging from 0 (no perceptible odor) to 4 (strong odor). The GC/MS analysis allowed to recognize VOCs characteristics of the investigated matrix belonging to the following chemical classes: alkanes, aldehydes, ketones, terpenes, and hydrocarbons. The odor evaluation and the simultaneous identification via GC/MS-O allowed to identify 2-propanone, $m, p$-xylene, $o$-xylene, delta-3-carene, 1,2,3-trimethylbenzene, 1,3,5-trimethylbenzene, and ethyltoluene as the odor-active VOCs responsible for the overall perceived odor. The overlapping of the chromatogram with the aromagram shows that many odorous stimuli perceived by the assessors at the ODP (listed in Table 1 as "unidentified") were not identified as no chromatographic peaks were simultaneously visualized during the analysis. This experimental evidence demonstrates that, in certain cases, sensory detection is more efficient than the analytical one. Other odor-active VOCs were detected at ODP but remained unrecognized due to the chromatogram complexity and the overlapping of coeluting compounds resulting in a confidence rating of mass spectra comparison lower than the reference value (95\%). On the contrary, although some compounds were characterized by high peaks in the chromatogram, odor stimuli were not perceived by panelists, probably because their concentration at the ODP was lower than the odor threshold (e.g., camphene, $\alpha$-terpinene). The aforementioned integrated approach, involving air sampling only during the nuisance events, overcomes the limitations of the conventional approaches and the lack of instrumental sensitivity and allows to identify in a more accurate way the chemical compounds contributing to the odor annoyance. In fact, even if qualitative information is only available, the chemical fingerprint of odor emission allows to recognize it and provide also useful information to plant managers for process control.

2.3. Case Study 2: Monitoring VOCs and Odor Annoyance in Residential Areas near a Gas and Oil Pretreatment Plant.
An innovative methodological approach was developed in order to study the critical residential area around the gas and oil pretreatment plant in Viggiano (PZ) (Figure 2).

Taking into account that citizens often alerted about odor annoyance and that adverse effects on human health such as eyes and upper airways irritation as well as difficulty in breathing were frequently denounced and registered, a solution to face this environmental and social issue was required to stakeholders, politicians, and scientific community [22]. Conventional methodological approaches for air pollution monitoring applied in previous investigations in the area failed in source emissions identification because the industrial area of Viggiano is mainly characterized by several and unpredictable fugitive emissions. Odor emission events occurring in that area are generally short term and thus difficult to detect by conventional approaches $[18,20]$. Moreover, the citizen perception of these odor events also depends on meteorological conditions, especially wind speed and direction that are characterized by high temporal variability. Therefore, in order to overcome all these limitations, an innovative methodological approach based on high temporal and spatial resolution was developed with the aim to map the territory and to obtain a real-time representation of pollution events. A monitoring campaign was carried out from 1 February to 30 June 2017.

The monitoring strategy implied the use of a smart sensor network consisting of eight photoionization detectors (PIDs; LabService Analytica srl) placed at different distances around the plant as shown in Figure 3. More specifically, seven PIDs (1-4 and 6-8) were installed in the populated area around the plant, at different distances from it. The last PID called "number 5" was installed on the hill in the center of the Viggiano urban settlement in order to be representative of background VOCs concentrations. The distance between each monitoring site and the COVA ranged from about 2.4 (PID 2) to 6.5 (PID 5) $\mathrm{km}$ as the crow flies. In correspondence with PID number $3(4.1 \mathrm{~km}$ as the crow flies from the COVA), meteorological sensors were also installed. This approach allowed to obtain VOCs concentration-time profiles as well as a mapping of the territory [20]. Moreover, in order to validate and confirm citizen alerts, odor impact assessment was carried out by means of the telephonic system able to systematize the population complaints. Each citizen georeferenced on the map and communicated the odor perception and its intensity on the basis of a three-level intensity scale with different colors (Figure 4).

The preliminary analysis of collected data showed a strong correlation among VOCs concentration, citizen alerts, and wind direction. In particular, when citizens used the telephonic system in order to communicate their odor perception, high VOCs concentrations (higher than $1 \mathrm{ppm}$ ) were registered by the PIDs located downwind the industrial plant. As an example, results obtained by the application of the high temporal and spatial resolution monitoring approach on a specific event day (15 April 2017) are reported in Figure 5. This figure represents a typical output showing the integration of information obtained by using different technologies. As it is possible to observe, high VOCs concentrations, with maximum ranging from $396 \mathrm{ppb}$ (PID 6) to 


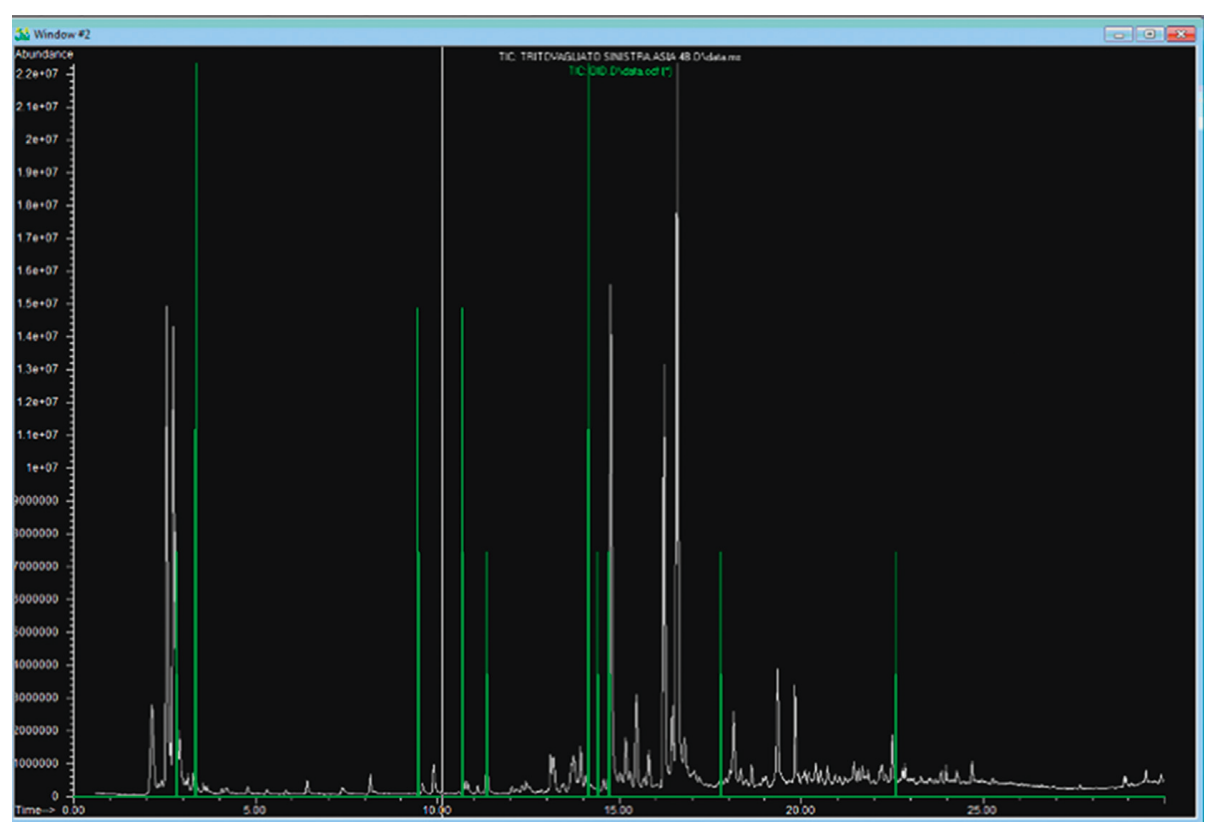

Figure 1: GC/MS-O analysis of air samples taken from an urban solid waste plant. The aromagram (green) overlapped with the GC/MS chromatogram (TIC, white).

TABLE 1: GC/MS-O analysis report.

\begin{tabular}{|c|c|c|c|}
\hline Compound & Retention time (min) & Odor description & Odor Intensity \\
\hline Dimethyl ether & 2.55 & & \\
\hline 2-Propanone & 2.73 & Solvent & 2 \\
\hline Methyl ethanoate & 2.90 & & \\
\hline Cyclopentane & 3.13 & & \\
\hline Ethyl acetate & 3.55 & & \\
\hline Methyl ethyl ether & 3.66 & & \\
\hline 2-Methylbutanal & 4.06 & & \\
\hline Heptane & 4.78 & & \\
\hline Methyl butanoate & 5.31 & & \\
\hline Dimethyl disulfide & 5.83 & & \\
\hline Toluene & 6.40 & & \\
\hline Octane & 7.38 & & \\
\hline Ethylbenzene & 9.60 & & \\
\hline$m, p$-Xylene & 9.90 & Sweet & 2 \\
\hline Styrene & 10.75 & & \\
\hline$o$-Xylene & 10.85 & Sweet & 2 \\
\hline Nonane & 11.10 & & \\
\hline$\Delta$-3-Carene & 11.31 & Fresh, herbaceous & 1 \\
\hline 1,2,4-Trimethylbenzene & 12.15 & & \\
\hline Octatriene & 12.31 & & \\
\hline 2,6-Dimethyloctane & 12.56 & & \\
\hline 5,6-Dimethyl-1,3-cyclohexadiene & 13.11 & & \\
\hline Camphene & 13.20 & & \\
\hline Propylbenzene & 13.40 & & \\
\hline$\beta$-Pinene & 13.93 & & \\
\hline 1,2,3-Trimethylbenzene & 14.07 & Aromatic/strong & 3 \\
\hline Ethyltoluene & 14.26 & Solvent & 2 \\
\hline 1,3,5-Trimethylbenzene & 14.48 & Aromatic/strong & 3 \\
\hline$\alpha$-Terpinene & 16.25 & & \\
\hline 1-Methyl-4-(1-methyethyl)-cyclohexene & 16.46 & & \\
\hline Unidentified & 17.53 & Burnt & 3 \\
\hline$\gamma$-Terpinene & 18.15 & & \\
\hline$\alpha$-Terpinolene & 19.34 & & \\
\hline Undecane & 19.84 & & \\
\hline Unidentified & 22.34 & Sweet & 2 \\
\hline Dodecane & 22.50 & & \\
\hline
\end{tabular}




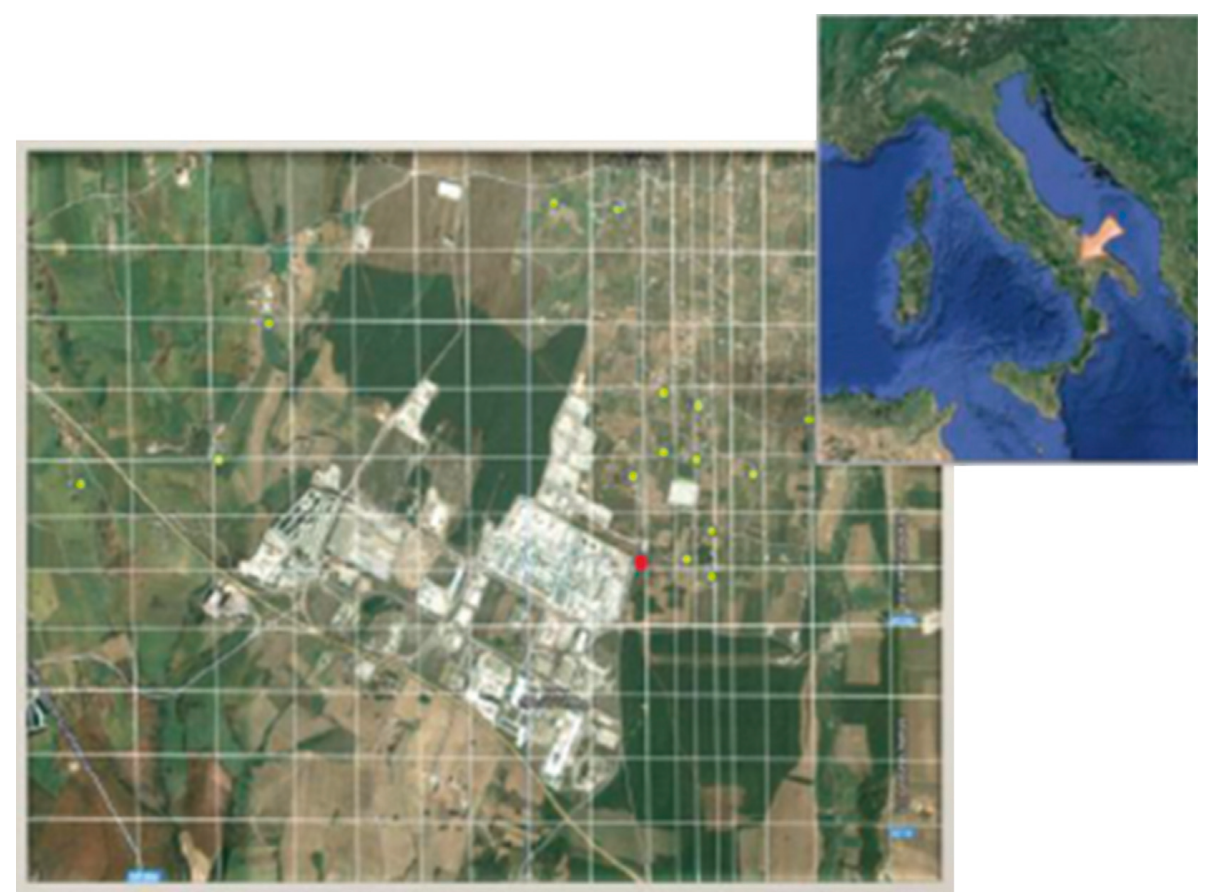

FIgURE 2: Gas and oil pretreatment plant (red point) and its position in the south of Italy.

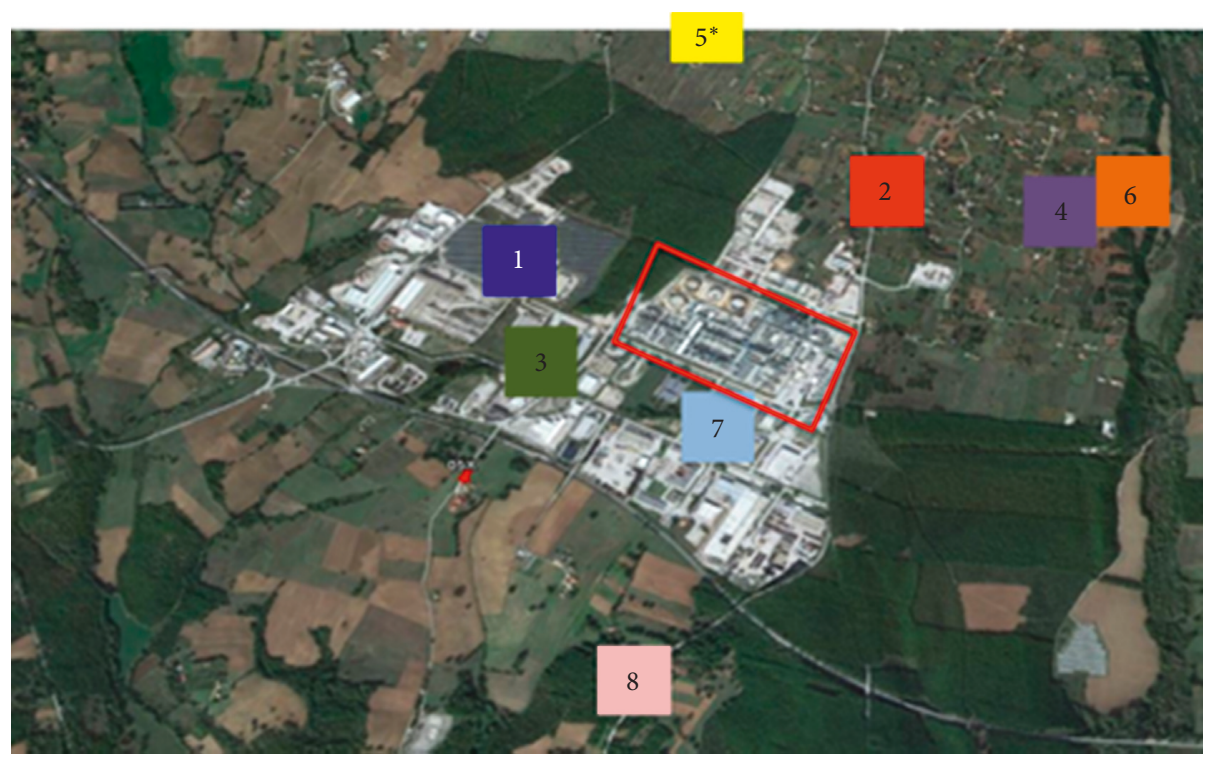

FIgURE 3: Gas and oil pretreatment plant (red square) and the smart sensor network.

$809 \mathrm{ppb}$ (PID 4) and $1.03 \mathrm{ppm}$ (PID 2), were registered from 11:00 AM to 6:00 PM. In the same hours, eleven citizens living close to aforementioned PIDs denounced intense odor annoyance by the telephonic system. Finally, the data about wind direction and speed confirmed the information derived by the integration of VOCs concentrations and citizens' alerts. In fact, the three receptors (PIDs 2, 4, and 6) were downwind with respect to the industrial plant allowing to identify the emission source (Figure 6).

\section{Conclusions}

The innovative and automatic monitoring approaches, developed in this study, are proven to be useful tools to collect real-time information about the emission sources and their potential impacts on the urban settlement. The application of this approach allowed to map the territory under investigation and to discriminate between local and industrial sources, also very close to each other. The integration of new 


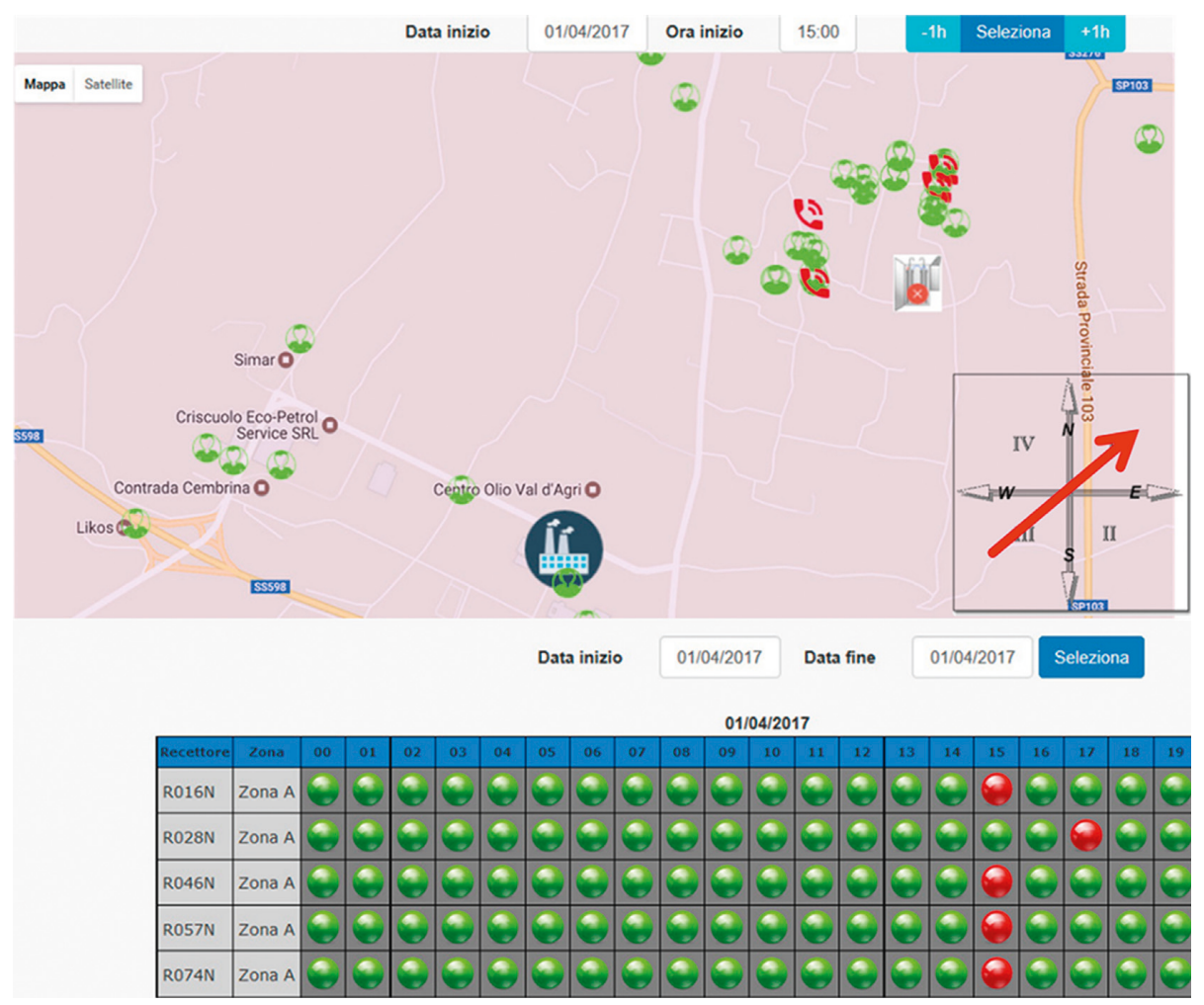

Figure 4: Typical output of the telephonic system.
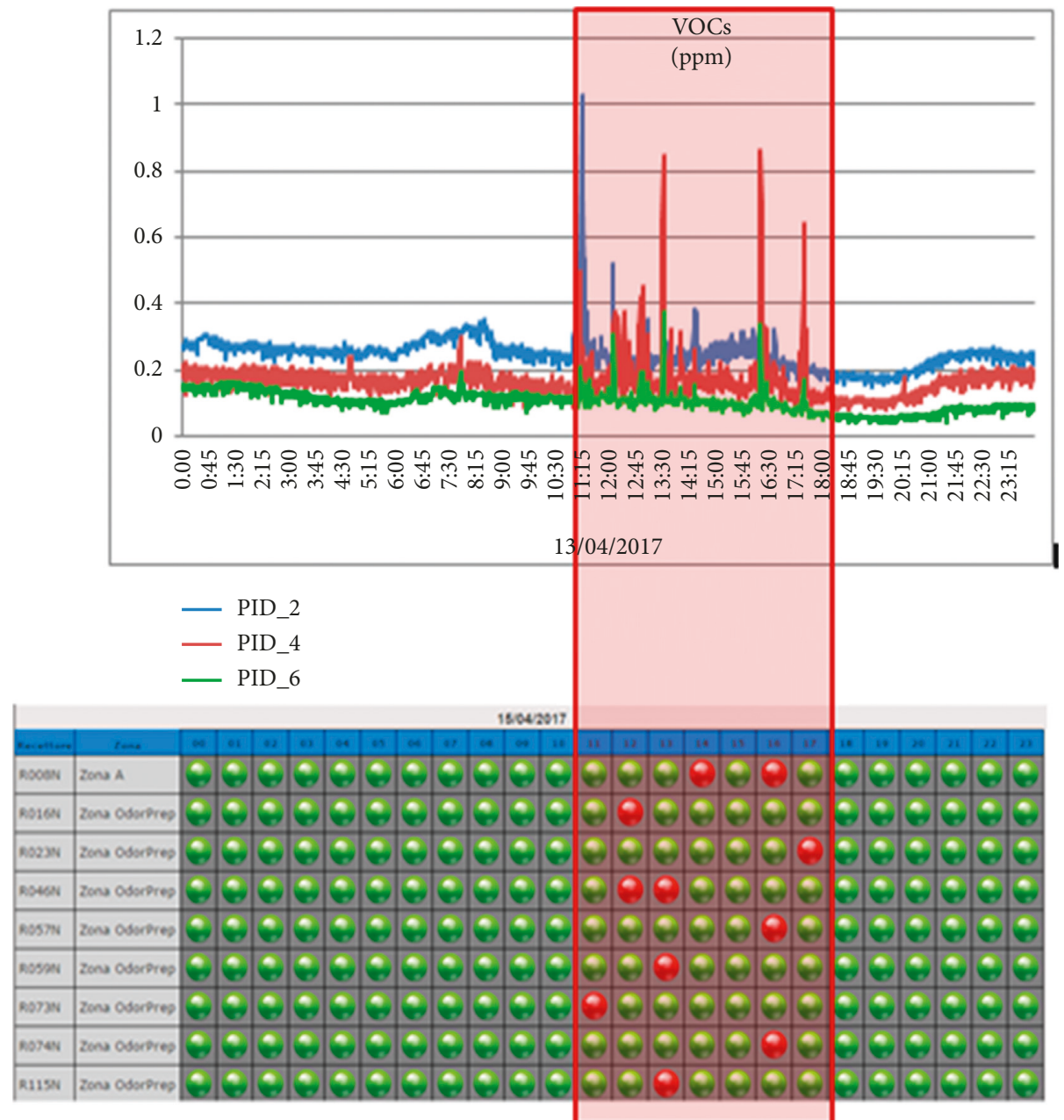

Figure 5: VOCs concentrations (PIDs 2, 4, and 6) in ppm and telephonic system output for the odor event on 15 April 2017. 


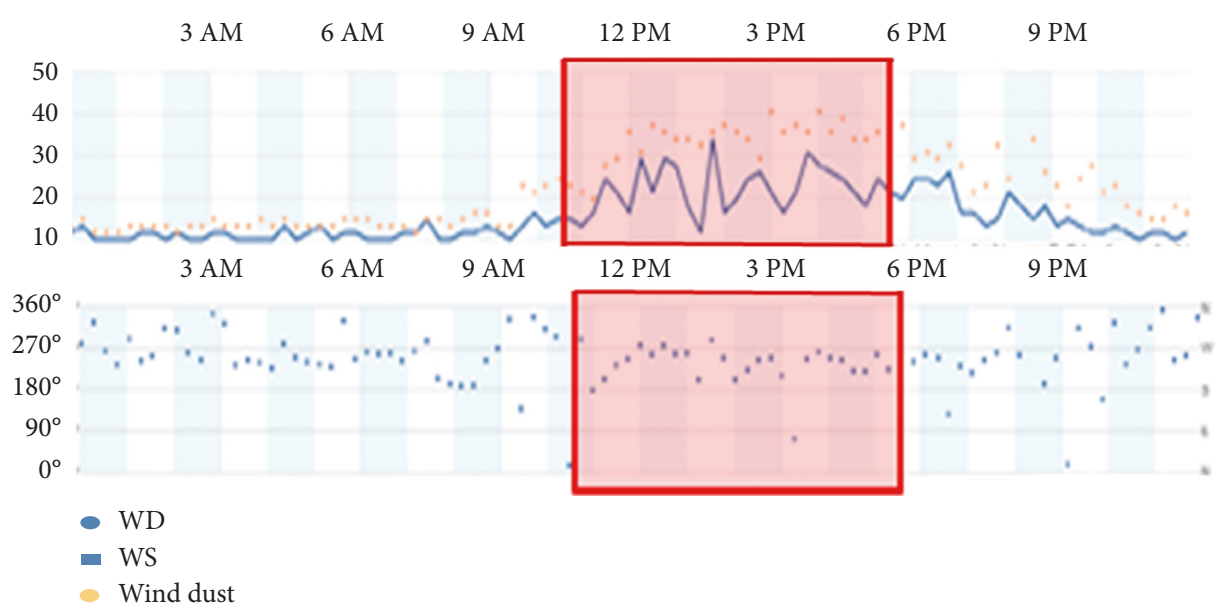

FIgUre 6: Wind speed (WS) and wind direction (WD) during the odor event on 15 April 2017.

and different technologies able to provide real-time information about the emissive sources and the odor annoyance perceived by the exposed population revealed to be strategic to (1) identify pollution events, even if short term; (2) collect air samples only during the nuisance events in order to obtain a representative sample of the real odor annoyance; and (3) increase the efficiency of odor-active VOCs chemical detection.

\section{Data Availability}

The data used to support the findings of this study are available from the corresponding author upon request.

\section{Conflicts of Interest}

The authors declare that there are no conflicts of interest regarding the publication of this paper.

\section{Acknowledgments}

This study was performed as part of the employment of the authors Dr Gianluigi de Gennaro, Alessia Di Gilio, and Dr Jolanda Palmisani. The monitoring approach developed and applied around the petroleum plant in Viggiano (PZ) was founded by the municipality of Viggiano and Grumento Nova (Italy) in framework of the project aimed to evaluate the impact of petroleum plant on human health of exposed population ("VIS_VG_VdA"). Moreover, the authors thank LabService Analytica srl and in particular Dr. Fornaro Antonio and Dr. Ivano Battaglia for providing their precious technical support in all phases of this study.

\section{References}

[1] M. Brattoli, E. Cisternino, P. R. Dambruoso et al., "Gas chromatography analysis with olfactometric detection (GC$\mathrm{O})$ as a useful methodology for chemical characterization of odorous compounds," Sensors, vol. 13, no. 12, pp. 1675916800, 2013.
[2] E. Davoli, M. L. Gangai, L. Morselli, and D. Tonelli, "Characterisation of odorants emissions from landfills by SPME and GC/MS," Chemosphere, vol. 51, no. 5, pp. 357-368, 2003.

[3] F. Dincer, M. Odabasi, and A. Muezzinoglu, "Chemical characterization of odorous gases at a landfill site by gas chromatography-mass spectrometry," Journal of Chromatography A, vol. 1122, no. 1-2, pp. 222-229, 2006.

[4] M. Aatamila, P. K. Verkasalo, M. J. Korhonen et al., "Odour annoyance and physical symptoms among residents living near waste treatment centres," Environmental Research, vol. 111, no. 1, pp. 164-170, 2011.

[5] S. P. Beghi, J. M. Santos, N. C. Reis, L. M. de Sá, E. V. Goulart, and E. de Abreu Costa, "Impact assessment of odours emitted by a wastewater treatment plant," Water Science and Technology, vol. 66, no. 10, pp. 2223-2228, 2012.

[6] C. R.-N. González, E. Björklund, R. Forteza, and V. Cerdà, "Volatile organic compounds in landfill odorant emissions on the island of Mallorca," International Journal of Environmental Analytical Chemistry, vol. 93, no. 4, pp. 434-449, 2013.

[7] C. E. W. Herr, A. zur Nieden, R. H. Bödeker, U. Gieler, and T. F. Eikann, "Ranking and frequency of somatic symptoms near composting sites with odor annoyance," International Journal of Hygiene and Environmental Health, vol. 206, no. 1, pp. 61-64, 2003.

[8] L. Li, C. Han, B. Guo, and Y. Zhou, "Comprehensive monitoring and assessment of odour emission sources from refinery I. monitoring of odorous sources," Petroleum Processing and Petrochemical, vol. 44, pp. 95-101, 2013.

[9] G. P. Macey, R. Breech, M. Chernaik et al., "Air concentrations of volatile compounds near oil and gas production: a community-based exploratory study," Environmental Health, vol. 13, no. 1, p. 82, 2014.

[10] E. F. Bazen and R. A. Fleming, "An economic evaluation of livestock odor regulation distances," Journal of Environment Quality, vol. 33, no. 6, pp. 1997-2006, 2004.

[11] E. Cetin, M. Odabasi, and R. Seyfioglu, "Ambient volatile organic compound (VOC) concentrations around a petrochemical complex and a petroleum refinery," Science of the Total Environment, vol. 312, no. 1-3, pp. 103-112, 2003.

[12] P. D. Kalabokas, J. Hatzaianestis, J. G. Bartzis, and P. Papagiannakopoulos, "Atmospheric concentrations of saturated and aromatic hydrocarbons around a Greek oil refinery," Atmospheric Environment, vol. 35, no. 14, pp. 2545-2555, 2001. 
[13] L. W. Libby and J. S. Sharp, "Land-use compatibility, change, and policy at the rural-urban Fringe: insights from social capital," American Journal of Agricultural Economics, vol. 85, no. 5, pp. 1194-1200, 2003.

[14] V. Blanes-Vidal, M. N. Hansen, A. P. S. Adamsen, A. Feilberg, S. O. Petersen, and B. B. Jensen, "Characterization of odor released during handling of swine slurry: Part I. Relationship between odorants and perceived odor concentrations," Atmospheric Environment, vol. 43, no. 18, pp. 2997-3005, 2009.

[15] V. Blanes-Vidal, H. Suh, E. S. Nadimi et al., "Residential exposure to outdoor air pollution from livestock operations and perceived annoyance among citizens," Environment International, vol. 40, pp. 44-50, 2012.

[16] P. Dambruoso, G. de Gennaro, A. Di Gilio, J. Palmisani, and M. Tutino, "The impact of infield biomass burning on PM levels and its chemical composition," Environmental Science and Pollution Research, vol. 21, no. 23, pp. 13175-13185, 2014.

[17] M. Amodio, E. Andriani, P. R. Dambruoso et al., "A monitoring strategy to assess the fugitive emission from a steel plant," Atmospheric Environment, vol. 79, pp. 455-461, 2013.

[18] A. Di Gilio, G. de Gennaro, P. Dambruoso, and G. Ventrella, "An integrated approach using high time-resolved tools to study the origin of aerosols," Science of the Total Environment, vol. 530-531, pp. 28-37, 2015.

[19] L. Capelli, S. Sironi, and R. Del Rosso, "Electronic noses for environmental monitoring applications," Sensors, vol. 14, no. 11, pp. 19979-20007, 2014.

[20] A. Di Gilio, G. Ventrella, P. Giungato et al., "An intensive monitoring campaign of PAHs for assessing the impact of a steel plant," Chemosphere, vol. 168, pp. 171-182, 2017.

[21] EN 13725, Air Quality-Determination of Odor Concentration by Dynamic Olfactometry, Committee for European Normalization (CEN), Brussels, Belgium, 2003.

[22] M. Faruolo, I. Coviello, C. Filizzola, T. Lacava, N. Pergola, and V. Tramutoli, "A satellite-based analysis of the Val d'Agri (South of Italy) Oil Center gas flaring emissions," Natural Hazards and Earth System Sciences Discussions, vol. 2, no. 6, pp. 4101-4133, 2014. 

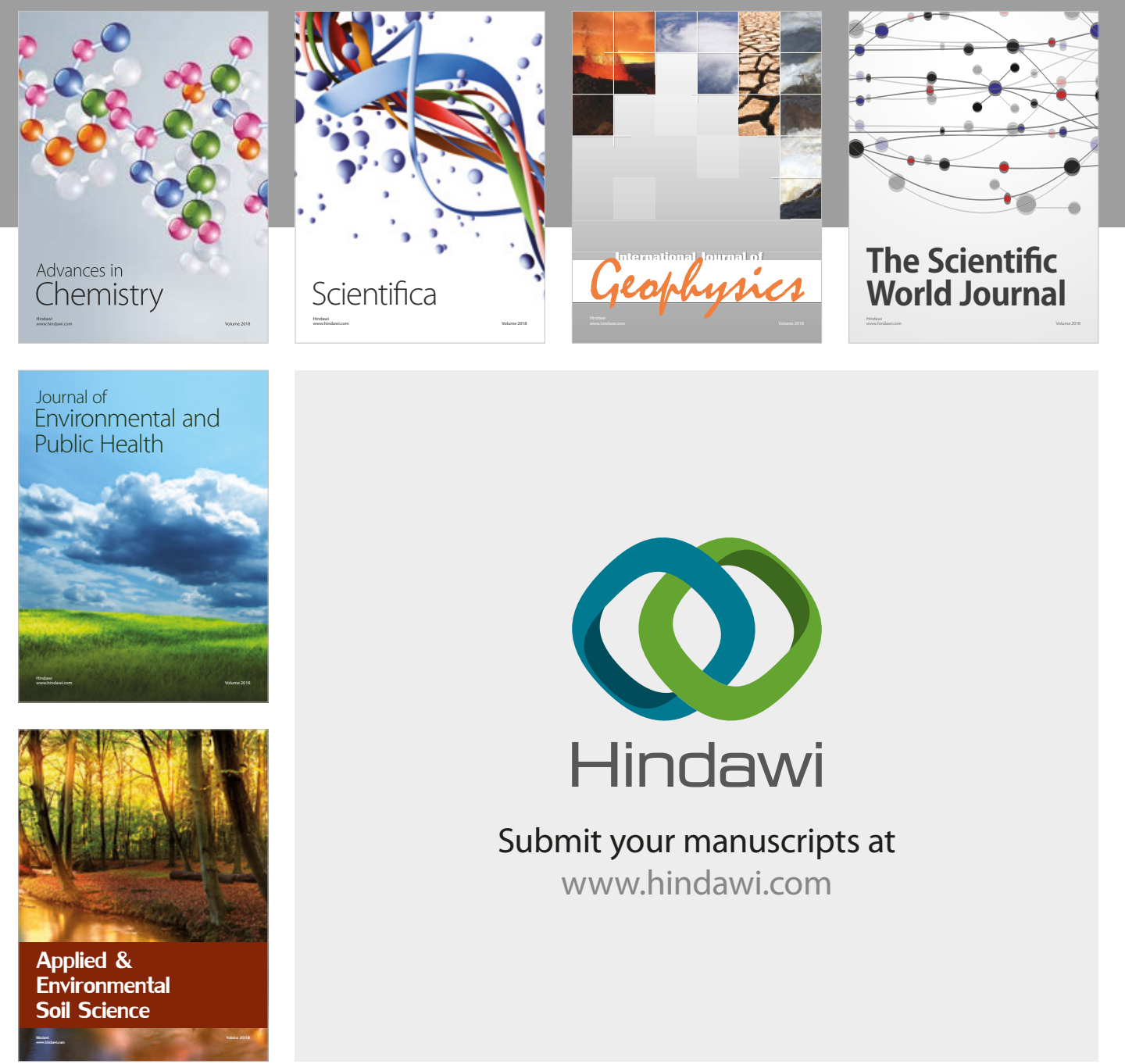

The Scientific

\section{World Journal}
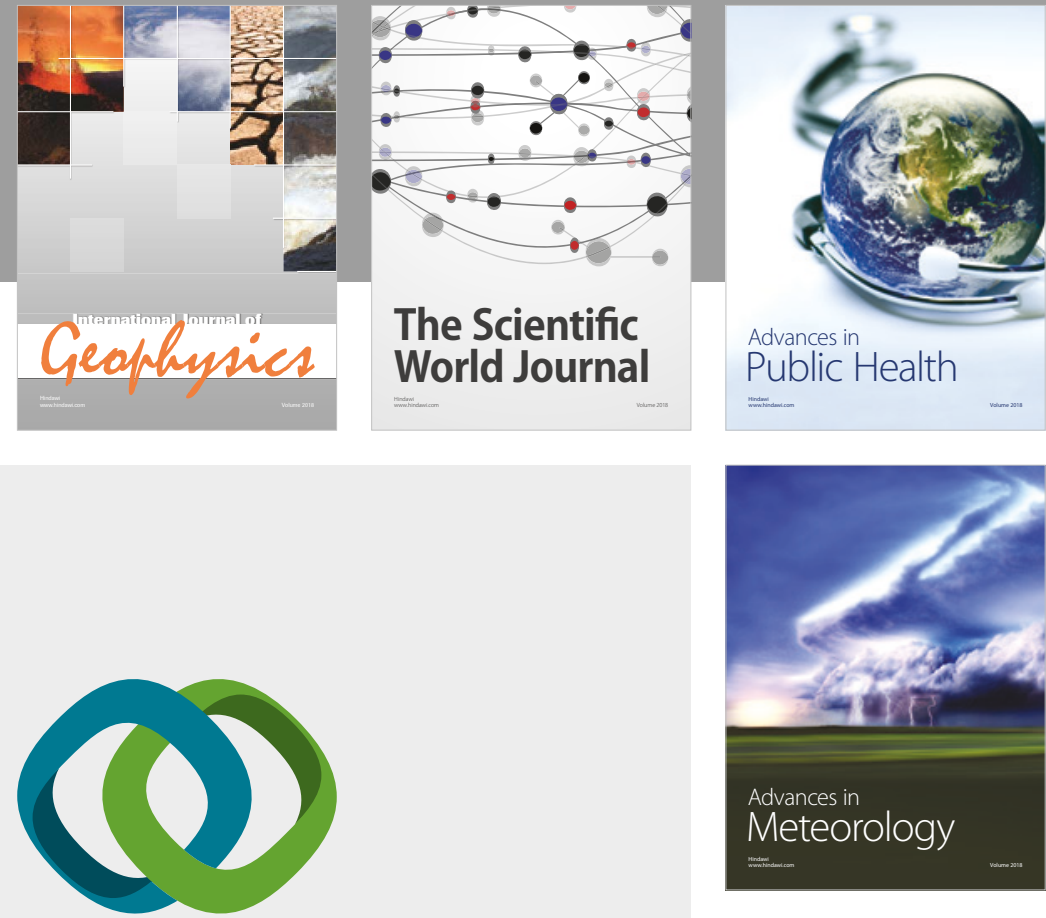

Advan

Public Health

\section{Hindawi}

Submit your manuscripts at

www.hindawi.com
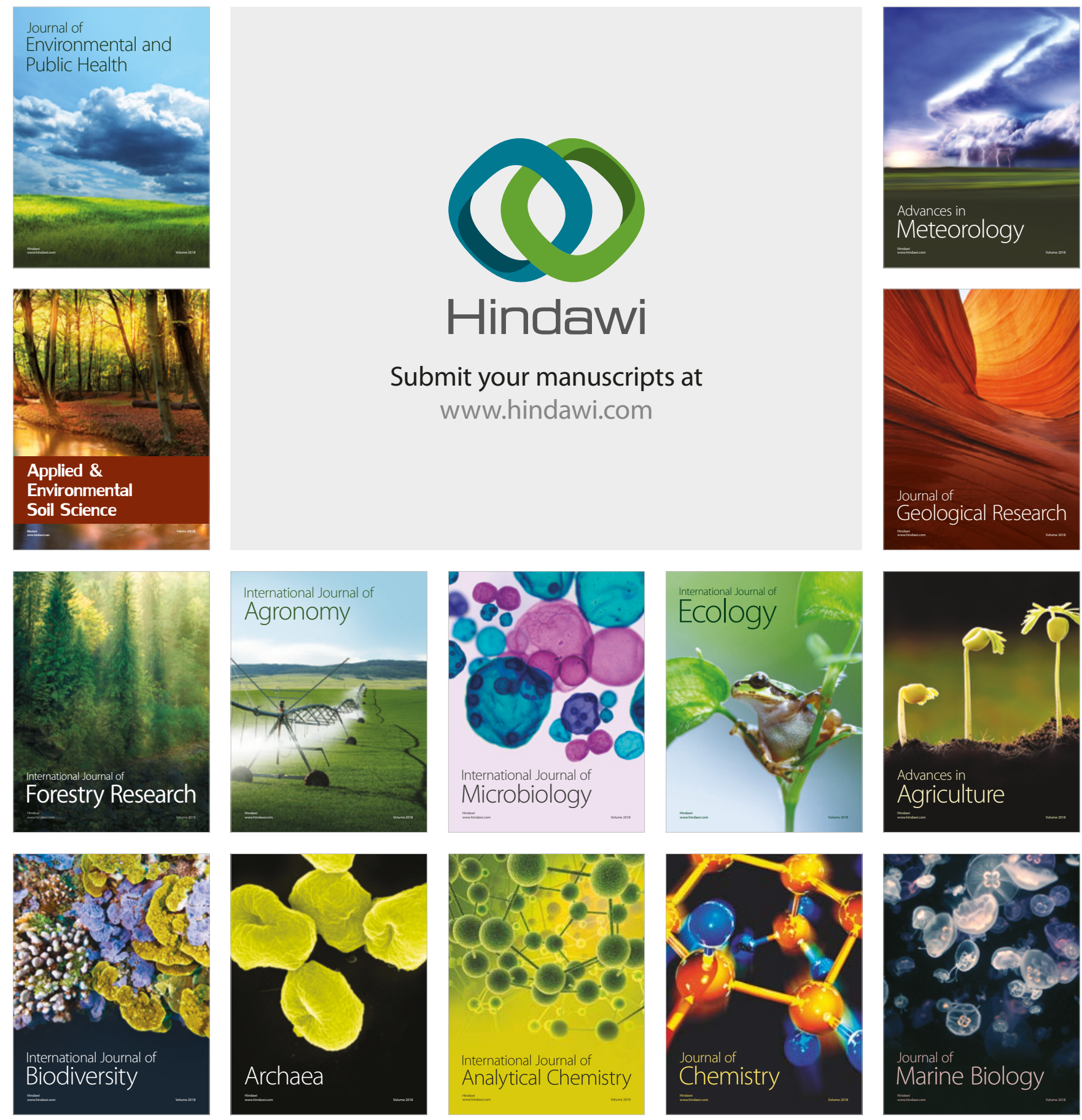